\title{
Identification of key bioactive anti-migraine constituents of Asari radix et rhizoma using network pharmacology and nitroglycerin-induced migraine rat model
}

\author{
Ting Huang ${ }^{1}$, Zhong-Hua Dai ${ }^{2}$, Fei Long ${ }^{1}$, Yu-Tian Lei ${ }^{1}$, Mao-Hua Yuan ${ }^{1,3}$, Gui- \\ Hua Jiang ${ }^{1 *}$ \\ ${ }^{1}$ College of Pharmacy, Chengdu University of Traditional Chinese Medicine, Chengdu 611137, ${ }^{2}$ Guangxi Key Laboratory of \\ Zhuang and Yao Ethnic Medicine, Collaborative Innovation Center of Zhuang and Yao Ethnic Medicine, Guangxi University of \\ Chinese Medicine, Nanning 530200; ${ }^{3}$ Traditional Chinese Medicine Detection, Leshan Food and Drug Inspection and Testing \\ Center, Leshan 614000, PR China
}

*For correspondence: Email: 11469413@qq.com

Sent for review: 27 October 2020

Revised accepted: 25 April 2021

\begin{abstract}
Purpose: To elucidate the bioactive constituents of Asari radix et rhizoma (ARR) in treating migraine based on network pharmacology and nitroglycerin-induced migraine rat model.

Methods: The potential bioactive constituents of ARR were identified with the aid of literature retrieval and virtual screening, and the migraine-related hub genes were identified using protein-protein interaction and topology analyses. Then, the interaction between the potential bioactive constituents and hub genes was determined with molecular docking and topology, leading to the prediction of the anti-migraine constituents of ARR. Moreover, a rat model of nitroglycerin-induced migraine was used to confirm the prediction by measuring the frequency of head-scratching and head-shaking behavior (FHHB) in the rats. In addition, levels of nitric oxide (NO) and calcitonin gene-related peptide (CGRP) in blood, norepinephrine (NE) and 5-hydroxytryptamine (5-HT) in brain were measured using appropriate commercial kits.

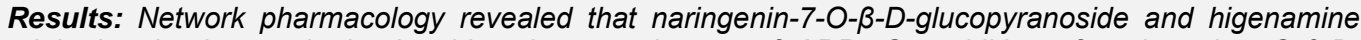
might be the key anti-migraine bioactive constituents of $A R R$. On addition of naringenin-7-O- $\beta-D-$ glucopyranoside or higenamine to $A R R$, there was marked enhancement of the mitigating effect of $A R R$ on nitroglycerin-induced abnormalities in levels of NO, CGRP, 5-HT and NE, as well as FHHB in rats ( $p$ $<0.05$ or 0.01 ).

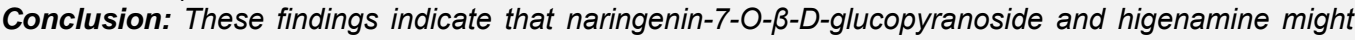
be the key bioactive and anti-migraine constituents of ARR. However, in addition to naringenin-7-O- $\beta-D-$ glucopyranoside and higenamine, there were many other anti-migraine constituents in ARR. Therefore, there is need for further investigations on the actual contributions of these two constituents of ARR in treating migraine.
\end{abstract}

Keywords: Asari radix et rhizoma, Migraine, Bioactive constituents, Network pharmacology, Bioactivity

This is an Open Access article that uses a fund-ing model which does not charge readers or their institutions for access and distributed under the terms of the Creative Commons Attribution License (http://creativecommons.org/licenses/by/4.0) and the Budapest Open Access Initiative (http://www.budapestopenaccessinitiative.org/read), which permit unrestricted use, distribution, and reproduction in any medium, provided the original work is properly credited.

Tropical Journal of Pharmaceutical Research is indexed by Science Citation Index (SciSearch), Scopus, International Pharmaceutical Abstract, Chemical Abstracts, Embase, Index Copernicus, EBSCO, African Index Medicus, JournalSeek, Journal Citation Reports/Science Edition, Directory of Open Access Journals (DOAJ), African Journal Online, Bioline International, Open-J-Gate and Pharmacy Abstracts 


\section{INTRODUCTION}

Migraine is a primary intermittent headache featured by varying combinations of symptoms related to gastrointestinal, neurological and autonomic changes [1]. Migraine patients often show some characteristic symptoms such as cutaneous allodynia, phonophobia, photophobia, and gastrointestinal symptoms (nausea and emesis) [2]. The patients may have other multifarious neurological symptoms such as vertigo, tinnitus, dizziness and cognitive impairment [3]. Migraine brings great mental and economic burden to patients. Therefore, it is necessary to develop anti-migraine drugs with safety and efficiency. At present, some significant progress has been made in the development of anti-migraine drugs. Traditional Chinese Medicines (TCMs) are extensively used for the treatment of migraine in China. Studies have indicated that TCMs had good effect and tolerance in the preventive treatment of migraine [4]. Asari Radix et Rhizoma (ARR) is frequently used in TCM clinics for the treatment of migraine. However, the bioactive anti-migraine constituents of ARR have not been elucidated.

Network pharmacology, a efficient and systematic tool, is a paradigm shift in drug discovery from "one constituent-one target" to "multi-constituents-multi-targets", and it is used to investigate the mechanisms of action and bioactive constituents of TCMs $[5,6]$. It has been successfully applied in the elucidation of TCMrelated issues, due to the fact that its characteristics are consistent with the holistic theory of TCMs [7,8]. Presently, network pharmacology is extensively applied to investigate the bioactive constituents of TCMs [911].

Therefore, this work was intended for determining the bioactive constituents of ARR involved in its anti-migraine properties, based on network pharmacology and nitroglycerin-induced rat model of migraine. Figure 1 shows the flow of work.

\section{EXPERIMENTAL}

\section{Plant material, chemicals and reagents}

Asari radix et rhizoma (ARR), the root and rhizome of Asarum heterotropoides Fr. Schmidt var. mandshuricum (Maxim.) Kitag., was purchased from a TCM market in Caiyuanba, Chongqing. The samples were identified by Prof Gui-Hua Jiang, a taxonomist in the College of Pharmacy, Chengdu University of Traditional Chinese Medicine.

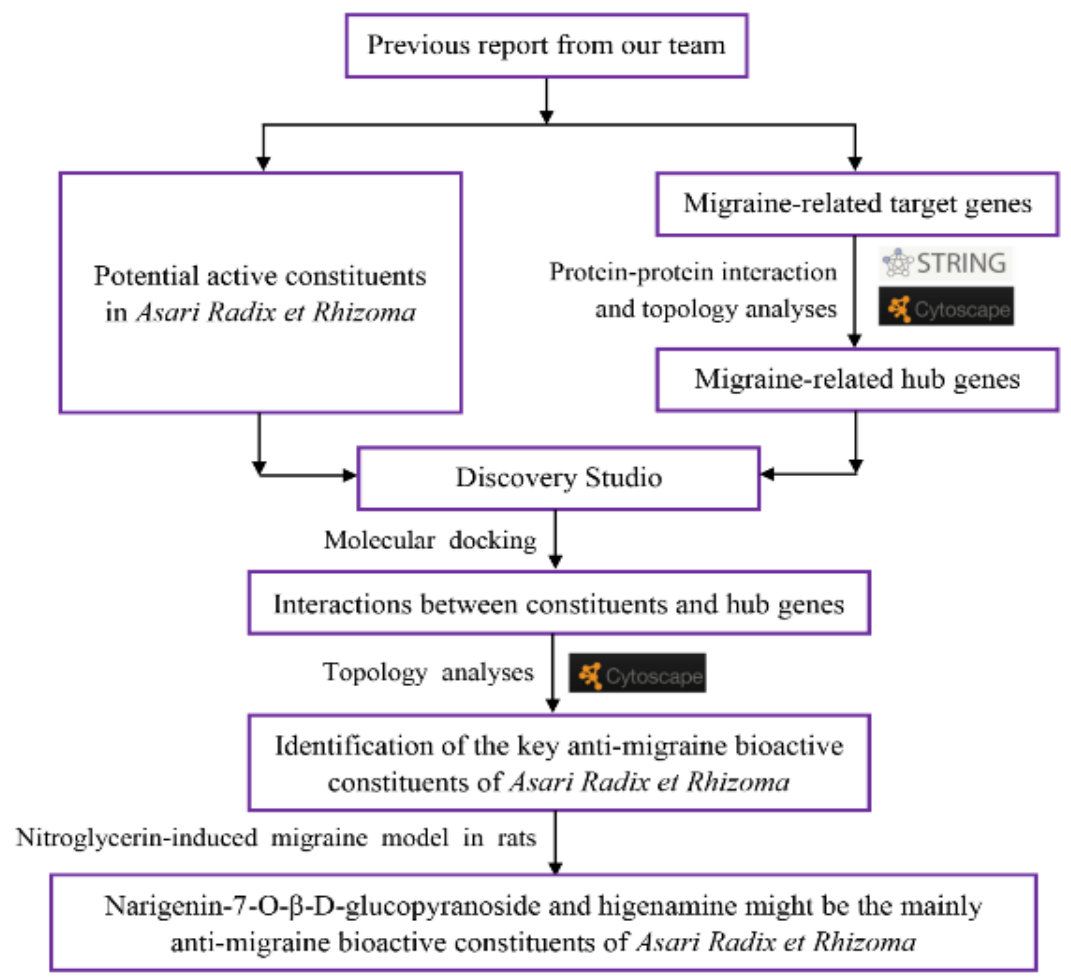

Figure 1: Workflow for deciphering the key anti-migraine bioactive constituents of Asari radix et rhizoma 
A voucher specimen of ARR (voucher no. CDUTCM-Jiang-ARR.2019) was deposited at the Herbarium of Chengdu University of Traditional Chinese Medicine for future reference. Chloral hydrate, flunarizine hydrochloride capsules, nitroglycerin injection, naringenin-7-O- $\beta-D-$ glucopyranoside and higenamine were purchased from Chron Chemicals (Chengdu, China), Janssen Pharmaceutical Ltd. (Xian, China), Yimin Pharmaceutical Co. Ltd. (Beijing, China), Yuanye Biotech (Shanghai, China) and Tauto Biotech (Shanghai, China), respectively. Assay kits for nitric oxide (NO) and calcitonin gene-related peptide (CGRP) were obtained from Jiancheng Bioengineering Institute (Nanjing, China). Kits for norepinephrine (NE) and 5hydroxytryptamine (5-HT) were bought from Jingruisi Biotechnology Co. Ltd. (Chengdu, China).

\section{Rats}

Specific pathogen-free male Sprague Dawley (SD) rats (mean weight $=200 \pm 20 \mathrm{~g}$ ) were bought from Dashuo Laboratory Animal Co. Ltd (Chengdu, China). The rats were feed in an animal house with relative humidity controlled at $40-70 \%$, temperature at $20-26{ }^{\circ} \mathrm{C}$, and 12-h light/12-h dark diurnal cycle, water and feed were given normally during the experiment. All animal treatments were implemented under the EU Directive 2010/63/EU [12]. In this study, all animal experiments were approved by the Institutional Animal Care and Use Committee of Chengdu University of Traditional Chinese Medicine (approval no. 2019-08).

Identification of constituents of ARR and migraine-related target genes

Based on a previous report [13], 259 constituents of ARR were identified from public databases and extant literature. Virtual screening for absorption, distribution, metabolism, excretion and toxicity (ADMET) indicated that 138 constituents exhibited good potential as bioactive constituents. 278 target genes related to migraine were identified from public databases. In addition, the 3D structures of the 138 constituents with good ADMET properties were obtained from the PubChem (https://pubchem.ncbi.nlm.nih.gov/), a free chemical database.

\section{Protein-protein interaction (PPI) network analysis of migraine-related target genes}

Analysis of PPI network is frequently used to appraise the hub genes of a group of genes. The PPI network analysis of 278 migraine-related target genes was performed on the STRING website (https://string-db.org/) using "Homo sapiens" setting, while the visualization and topology analysis of the PPI network were performed with Cytoscape ver. 3.7.1 (https://cytoscape.org/). The topology parameters (degree, closeness centrality and betweenness centrality) were used to identify the hub genes of 278 migraine-related target genes. The structures of proteins encoded by the hub genes were obtained from the PDB website (https://www.rcsb.org/) under "Homo sapiens" setting, based on UniProt ID or gene symbol.

\section{Establishment and network determination of interactions between constituents and hub genes}

Molecular docking was used to establish the interactions between the 138 constituents and migraine-related hub genes. The molecular docking program consisted of ligand processing (A), receptor processing (B) and docking calculation (C). All operations were carried out on Discovery Studio (DS) software. Interactions between constituents and hub genes were retained when the docking scores were $\geq 90$. Network visualization and topology analysis of the reserved interactions between constituents and genes were carried out on Cytoscape ver. 3.7.1, and the topology parameter (degree) was used to identify the key bioactive constituents related to the anti-migraine effect of $A R R$.

The 3D structures of the 138 constituents were processed by adding hydrogens and applying CHARMm forcefield. Water and ligand molecules in proteins of hub genes were deleted. Then, DS "Macromolecules|Prepare Protein|Clean Protein" function was used to remove multiple conformations, followed by supplementation of non-intact amino acid residues and addition of hydrogens of proteins. Subsequently, the binding site of each protein was defined based on original ligand position of protein or DS "Receptor-Ligand Interactions|Define and Edit Binding Site|From Receptor Cavities" function.

The DS "Receptor-Ligand Interactions|Dock Ligands|Dock Ligands (LibDock)" function was used to calculate the binging energies in molecular docking between ligands and receptors.

\section{Grouping and treatment of rats}

Ninety rats were divided into 9 groups randomly (Table 1). Rats in the low-dose, medium dose and high-dose ARR groups received ARR powder at doses of $0.08 \mathrm{~g} / \mathrm{kg}, 0.17 \mathrm{~g} / \mathrm{kg}$ and 0.33 
$\mathrm{g} / \mathrm{kg}$ body weight (bwt), respectively. Rats in ARR-N, ARR-H and ARR-N-H groups received the same dose of ARR powder $(0.8 \mathrm{~g} / \mathrm{kg} \mathrm{bwt})$ in addition to naringenin-7-O- $\beta$-D-glucopyranoside $(20.3 \mu \mathrm{g} / \mathrm{kg}$; ARR-N), or higenamine $(16.8 \mu \mathrm{g} / \mathrm{kg}$; ARR-H) or naringenin-7-O- $\beta$-D-glucopyranoside and higenamine $(20.3$ and $16.8 \mu \mathrm{g} / \mathrm{kg}$ bwt, respectively; ARR-N-H). Thus, the contents in ARR powder and higenamine in ARR-H and ARR-N-H groups were equal to the content of these components in the high-dose ARR group. This was aimed at ascertaining whether naringenin-7-O- $\beta$-D-glucopyranoside or higenamine was the bioactive constituent responsible for the anti-migraine property of ARR by comparing the anti-migraine effects in ARR-N, ARR-H and ARR-N-H groups with that in the lowor high-dose ARR groups.

The drugs were diluted with distilled water to obtain the pharmacodynamic samples, and rats in different groups were orally administered with corresponding drugs once a day for 7 days. After 30 min of drug therapy on day 7 , migraine model was established via subcutaneous injection (in the posterior neck) of the rats with nitroglycerin at a dose of $10 \mathrm{~mL} / \mathrm{kg}$, in addition to rats in normal group. Rats in normal group received equivalent dose normal saline at the same site, in place of nitroglycerin injection.

\section{Determination of behavioral and biochemical indices in rats}

Following treatment with nitroglycerin, the frequency of head-scratching and head-shaking behavior (FHHB) of rats in each group was determined within $2 \frac{1}{2} \mathrm{~h}$. Then, $8 \mathrm{~mL}$ blood was taken from the abdominal aorta of each rat that was anesthetized with $10 \%$ chloral hydrate (3.5 $\mathrm{mL} / \mathrm{kg}$ ). Subsequently, $5 \mathrm{ml}$ blood was allowed to coagulate naturally and centrifuged for $20 \mathrm{~min}$ (3000 rpm, $4{ }^{\circ} \mathrm{C}$ ). The serum sample was kept frozen at $-20^{\circ} \mathrm{C}$, prior to use in determination of $\mathrm{NO}$ with the aid of $\mathrm{NO}$ kit. Another $3 \mathrm{~mL}$ blood was mixed with anticoagulant (ethylenediaminetetraacetic acid) and centrifuged for $20 \mathrm{~min}\left(3000 \mathrm{rpm}, 4{ }^{\circ} \mathrm{C}\right)$. The plasma sample was frozen at $-20^{\circ} \mathrm{C}$ and used for determination of CGRP with CGRP kit.

After blood collection, the rats were sacrificed through decapitation, and their brains were immediately excised and placed in liquid nitrogen. Then, $1 \mathrm{~g}$ brain tissue was ground on ice with $9 \mathrm{~mL}$ normal saline, and the mixture was centrifuged for $20 \mathrm{~min}\left(3000 \mathrm{rpm}, 4{ }^{\circ} \mathrm{C}\right)$. Subsequently, the supernatant was kept at -20 ${ }^{\circ} \mathrm{C}$ for use in determination of $5-\mathrm{HT}$ and NE with their corresponding kits.
Table 1: Grouping and drug treatment of rats

\begin{tabular}{|c|c|c|}
\hline Groups & Treatment & Dose \\
\hline Normal & Distilled water & \\
\hline Model & Distilled water & \\
\hline Positive & $\begin{array}{l}\text { flunarizine } \\
\text { hydrochloride } \\
\text { capsules }\end{array}$ & $1 \mathrm{mg} / \mathrm{kg}$ \\
\hline $\begin{array}{l}\text { Low-dose } \\
\text { ARR }\end{array}$ & ARR powder & $0.08 \mathrm{~g} / \mathrm{kg}$ \\
\hline $\begin{array}{l}\text { Medium- } \\
\text { dose ARR }\end{array}$ & ARR powder & $0.17 \mathrm{~g} / \mathrm{kg}$ \\
\hline $\begin{array}{l}\text { High-dose } \\
\text { ARR }\end{array}$ & ARR powder & $0.33 \mathrm{~g} / \mathrm{kg}$ \\
\hline ARR-N & $\begin{array}{l}\text { ARR powder and } \\
\text { naringenin-7-O- } \beta-D- \\
\text { glucopyranoside }\end{array}$ & $\begin{array}{l}0.08 \mathrm{~g} / \mathrm{kg} \text { and } \\
20.3 \mu \mathrm{g} / \mathrm{kg}\end{array}$ \\
\hline ARR-H & $\begin{array}{l}\text { ARR powder and } \\
\text { higenamine }\end{array}$ & $\begin{array}{l}0.08 \mathrm{~g} / \mathrm{kg} \text { and } \\
16.8 \mu \mathrm{g} / \mathrm{kg}, \\
\text { respectively }\end{array}$ \\
\hline ARR-N-H & $\begin{array}{l}\text { ARR powder, } \\
\text { naringenin-7-O- } \beta-D- \\
\text { glucopyranoside } \\
\text { and higenamine }\end{array}$ & $\begin{array}{l}0.08 \mathrm{~g} / \mathrm{kg}, 20.3 \\
\mu \mathrm{g} / \mathrm{kg} \text { and } 16.8 \\
\mu \mathrm{g} / \mathrm{kg} \text {, } \\
\text { respectively }\end{array}$ \\
\hline
\end{tabular}

\section{Statistical analysis}

Data on FHHB of rats were consistent with abnormal distribution, and were converted to normally distributed data using log function. The log function value of the NHHB of rats was reported as mean \pm standard deviation (SD). The levels of NO, CGRP, 5-HT and NE in rats were consistent with normal distribution, and are reported as mean \pm standard deviation. Differences in these indices among groups were determined using ANOVA, followed by LSD multiple comparison. All statistical analyses were carried out with SPSS version 19.0. If $p<0.05$, the differences had statistical significance.

\section{RESULTS}

\section{Hub genes of 278 migraine-related target genes}

Results from STRING showed that the PPI network of 278 migraine-related target genes consisted of 257 nodes (genes) and 2305 edges (gene-gene interactions). It was visualized as shown in Figure 2, and analyzed using Cytoscape. Based on topology parameters (degree $\geq 40$, closeness centrality $\geq 0.48$ and betweenness centrality $\geq 0.02$ ), 15 hub genes were identified. The protein constructions of 13 hub genes were obtained from the PDB website. However, the protein constructions of the other 2 hub genes (GNB3 and TAC1) were not available. The gene symbol, UniProt ID and PDB ID of the 15 hub genes related to migraine are presented in Table 2. 


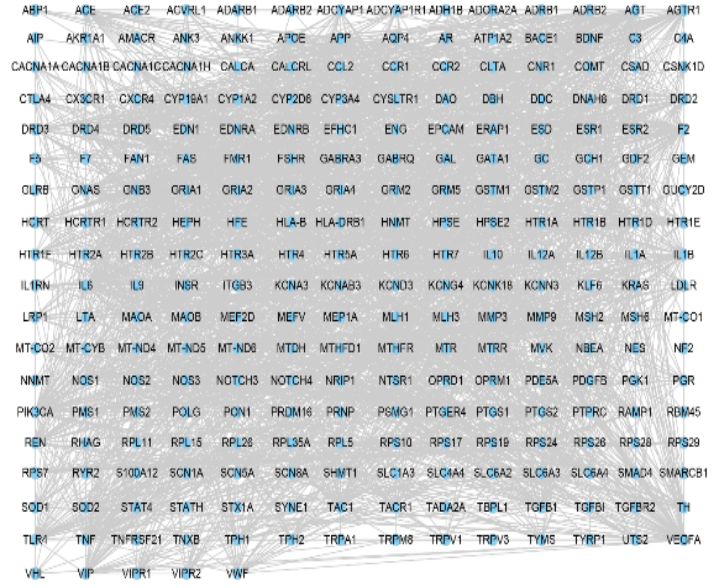

Figure 2: Network of migraine-related target genes with 257 nodes (genes) and 2305 edges (gene-gene interactions)

\section{Key anti-migraine bioactive constituents of ARR}

Results of molecular docking indicated that 238 interactions were identified between the 138 constituents and 13 migraine-related hub genes, while 69 constituents and 9 hub genes were involved in the 238 interactions. As shown in Figure 3, the 238 interactions were visualized using the network. Based on the degree value of each constituent, naringenin-7-O- $\beta$-Dglucopyranoside (PubChem CID: 92794), higenamine (PubChem CID: 114840), and 2,5furandione, 3-(dodecenyl) dihydro- (PubChem CID: 5362708) were connected to 8 huge genes,

Table 2: Gene symbol, UniProt ID and PDB ID of 15 migraine-related hub genes

\begin{tabular}{llllll}
\hline Gene & UniProt ID & PDB ID & Gene & UniProt ID & PDB ID \\
\hline IL6 & P05231 & 1ALU & TAC1 & P20366 & - \\
VEGFA & P15692 & 4KZN & EDN1 & P05305 & 1EDN \\
APP & P05067 & 2FMA & NOS3 & P29474 & 1M9M \\
GNB3 & P16520 & - & BDNF & P23560 & 1BND \\
TNF & P01375 & 2AZ5 & TGFB1 & P01137 & 5VQP \\
F2 & P00734 & 4LZ1 & CXCR4 & P61073 & 3ODU \\
PIK3CA & P42336 & 4JPS & ESR1 & P03372 & 1XP6 \\
AGT & P01019 & 2WXW & - & - & - \\
\hline
\end{tabular}

and the degree values of the 3 constituents were larger than those of the other 66 constituents in the network, indicating that the 3 constituents might be the key bioactive anti-migraine constituents of ARR. However, existing report indicate that 2,5-furandione, 3-(dodecenyl) dihydro- should be excluded because it is used mainly in the chemical industry [14]. Therefore, naringenin-7-O- $\beta$-D-glucopyranoside and higenamine might be the key bioactive antimigraine constituents of ARR.

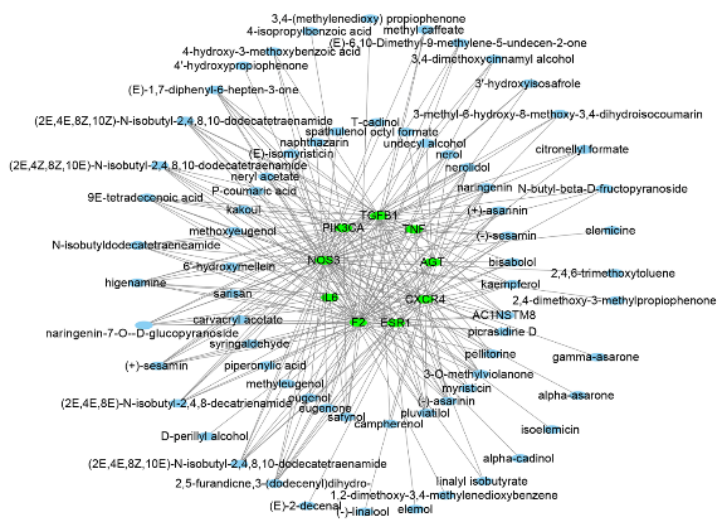

Figure 3: Network with 78 nodes (constituents or genes) and 238 edges (constituent-genes interactions) linking 69 constituents in Asari Radix et Rhizoma and 9 hub genes related to migraine

Effects of ARR, naringenin-7-O- $\beta-D-$ glucopyranoside and higenamine on the FHHB and levels of NO, CGRP, 5-HT and NE in blood or brain of rats with migraine

The levels of, NO, CGRP, 5-HT and NE, as well as $\mathrm{FHHB}$ in the model group were markedly higher than those in the normal group $(p<0.01)$. However, after treatment with flunarizine hydrochloride, ARR, ARR-N, ARR-H and ARR-N$H$, the nitroglycerin-induced abnormalities in FHHB and levels of NO, CGRP, 5-HT and NE in rats were reversed to normal significantly $(p<$ 0.05 ), except for the effect of low-dose ARR on $\mathrm{NO}$ level and FHHB. Results showed that the levels of most behavioral and biochemical indices in the ARR-N, ARR-H and ARR-N-H groups were markedly lower than those in the low-dose ARR group, but higher than those in the high-dose ARR group ( $p<0.05)$, with some exceptions. For instance, the $\mathrm{FHHB}$ and levels of CGRP in the ARR-N, ARR-H and ARR-N-H groups were close to those in the high-dose ARR group, except that the CGRP level in the ARR-N$\mathrm{H}$ group was below that in the high-dose ARR 
Table 3: Effects of ARR, naringenin-7-O- $\beta$-D-glucopyranoside and higenamine on NHHB, NO and CGRP in rats with migraine

\begin{tabular}{|c|c|c|c|}
\hline Group & FHHB & $\mathrm{NO}(\mu \mathrm{mol} / \mathrm{L})$ & CGRP (ng/L) \\
\hline Normal & $0.43 \pm 0.28$ & $28.93 \pm 7.00$ & $264.21 \pm 14.17$ \\
\hline Model & $1.85 \pm 0.24^{* *}$ & $141.65 \pm 19.29^{* *}$ & $485.89 \pm 56.86^{* *}$ \\
\hline Positive & $0.91 \pm 0.66^{\#}$ & $116.26 \pm 11.27^{\# \#}$ & $287.62 \pm 20.57^{\# \#}$ \\
\hline Low-dose ARR & $1.69 \pm 0.24$ & $133.63 \pm 17.26$ & $305.73 \pm 23.35^{\# \#}$ \\
\hline Medium-dose ARR & $1.44 \pm 0.35^{\#}$ & $114.19 \pm 6.20^{\# \#}$ & $301.02 \pm 15.79^{\# \#}$ \\
\hline High-dose ARR & $1.32 \pm 0.35^{\# \#}$ & $93.07 \pm 8.14^{\# \#}$ & $286.64 \pm 9.57^{\# \#}$ \\
\hline ARR-N & $1.47 \pm 0.30^{\#}$ & $106.50 \pm 8.56^{\# \# \triangle \&}$ & $262.07 \pm 8.33^{\# \# \Delta \Delta}$ \\
\hline ARR-H & $1.31 \pm 0.44^{\# \# \Delta}$ & $116.40 \pm 8.53^{\# \# \triangle \& \&}$ & $284.72 \pm 14.59^{\# \#}$ \\
\hline ARR-N-H & $1.42 \pm 0.25^{\#}$ & 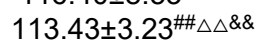 & $173.21 \pm 19.30^{\# \# \Delta \triangle \&}$ \\
\hline
\end{tabular}

Table 4: Effects of ARR, naringenin-7-O- $\beta-D-$ glucopyranoside and higenamine on $5-\mathrm{HT}$ and NE in rats with migraine

\begin{tabular}{lll}
\hline Group & $\mathbf{5 - H T}(\mathbf{n g} / \mathbf{m L})$ & NE $(\mathbf{p g} / \mathbf{m L})$ \\
\hline Normal & $85.33 \pm 6.99$ & $873.99 \pm 60.20$ \\
Model & $197.62 \pm 12.00^{* *}$ & $1805.59 \pm 72.28^{* *}$ \\
Positive & $96.28 \pm 7.19^{\# \#}$ & $1017.92 \pm 100.45^{\# \#}$ \\
Low-dose & $155.53 \pm 10.03^{\# \#}$ & $1499.69 \pm 104.06^{\# \#}$ \\
ARR & & \\
Medium- & $137.13 \pm 9.00^{\# \#}$ & $1335.10 \pm 71.94^{\# \#}$ \\
dose ARR & & \\
High-dose & $114.58 \pm 8.78^{\# \#}$ & $1184.02 \pm 86.50^{\# \#}$ \\
ARR & $164.52 \pm 12.74^{\# \# \&}$ & $1616.33 \pm 57.74^{\# \# \triangle \triangle \& \&}$ \\
ARR-N & $\&$ & \\
ARR-H & $145.69 \pm 11.71^{\# \&}$ & $1416.97 \pm 87.43^{\# \# \triangle \& \&}$ \\
ARR-N-H & $127.12 \pm 13.22^{\# \#}$ & $1244.90 \pm 78.43^{\# \# \triangle \Delta}$ \\
& $\Delta \&$ &
\end{tabular}

${ }^{* *} P<0.01$, compared with normal group; ${ }^{\# \#} p<0.01$, compared with model group; $\Delta p<0.05, \Delta \Delta p<0.01$, compared with low-dose ARR group; ${ }^{\&} p<0.05$, ${ }^{\&} \&_{p}<$ 0.01 , compared with high-dose ARR group. ARR: Asari Radix et Rhizoma; NE: norepinephrine: 5-HT, 5hydroxytryptamine

group significantly $(p<0.05)$. These results are shown in Tables 3 and 4.

\section{DISCUSSION}

The monitoring of bioactive constituents ensures the quality and effectiveness of TCMs. Asari Radix et Rhizoma (ARR) is frequently used for the treatment of migraine, but its bioactive constituents remain unclear. Therefore, the purpose of this research was to predict the key bioactive and anti-migraine constituents of ARR, based on network pharmacology. Thereafter, a rat migraine model induced by nitroglycerin was used to confirm the prediction. Network pharmacology-based prediction of the bioactive constituents of ARR responsible for its antimigraine effect was carried out by identification of potentially bioactive components, identification of migraine-related hub genes, and analysis of interactions between potentially bioactive constituents and the hub genes. The results showed that naringenin-7-O- $\beta-D$ glucopyranoside and higenamine might be the key bioactive and anti-migraine constituents of ARR. Based on literature retrieval, no studies have reported the effect of naringenin-7-O- $\beta-D-$ glucopyranoside or higenamine on migraine.

The nitroglycerin-induced migraine model in rats is a universally accepted model for investigation of the anti-migraine bioactive constituents of TCMs, and it supports the trigeminal-vascular theory, the current mainstream theory of the pathogenesis of migraine [15]. Head-scratching and head-shaking behavior (HHB) is a universally accepted index for evaluating successful establishment of nitroglycerin-induced migraine in rats, with the FHHB of rats with migraine being markedly higher than that of normal rats [16]. Trigeminal-vascular theory holds that neurogenic inflammation is the core feature of migraine, and neurogenic inflammation is related to changes in the vasoactive substances levels [17]. The release of calcitonin gene-related peptide (CGRP), the strongest vasodilator substance, enhances vasodilatation, mast cell degranulation and plasma protein extravasation, resulting in the trigeminal nerve inflammation [18]. The release of CGRP is enhanced by NO. Nitroglycerin releases NO through enzymatic and non-enzymatic reactions [19]. This confirms that the nitroglycerin-induced pain is a feasible method for establishing migraine in experimental animals.

There is very low level of free 5-HT in plasma, and its release is abnormally increased at the onset of migraine attack [20]. The 5-HT level in plasma is positively correlated with that in brain. Low levels of 5-HT indicate high affinity of the 5$\mathrm{HT}_{1 \mathrm{~B} / 1 \mathrm{D}}$ receptor, resulting in vasoconstriction and stabilization of the neurons of the perivascular 
nociceptor and the mid-axis nociceptors [21,22]. However, low levels of 5-HT indicate high affinity of the $5-\mathrm{HT}_{2 \mathrm{~A}}$ receptor, resulting in increases in NO levels [21,23]. Increased levels of NO promote migraine attack by enhancing the release of CGRP. Norepinephrine (NE), a monoamine neurotransmitter widely distributed in the nervous system, enhances vasoconstriction [24]. This relieves migraine attack. Generally, the level of NE is quickly increased at the onset of migraine attack to resist vasodilation, and then the level of NE decreases gradually. In brief, migraine attack may be attributed to interactions among NO, CGRP, 5-HT and NE. In the present study, ARR reversed the nitroglycerin-induced abnormalities in NO, CGRP, 5-HT and NE levels, as well as $\mathrm{FHHB}$ in rats, thereby confirming the anti-migraine effect of ARR.

To confirm whether naringenin-7-O- $\beta-D-$ glucopyranoside or higenamine was the bioactive constituent involved in the anti-migraine effect of $A R R$, differences in behavioral and biochemical indices between the low- or high-dose ARR groups, and ARR-N, ARR-H or ARR-N-H group were statistically analyzed. The FHHB and most of the biochemical indices in the ARR-N, ARR-H and ARR-N-H groups were markedly lower than those in the low-dose ARR group, suggesting

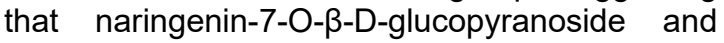
higenamine exerted anti-migraine effects. The levels of most indices in the ARR-N, ARR-H and ARR-N-H groups were markedly higher than or were close to those in the high-dose ARR group, suggesting that naringenin-7-O- $\beta-D-$ glucopyranoside and higenamine might be the key bioactive constituents responsible for the anti-migraine property of ARR.

\section{CONCLUSION}

The bioactive anti-migraine constituents of ARR have been investigated by network pharmacology and nitroglycerin-induced rat model of migraine. The findings indicate that naringenin-7-O- $\beta$-D-glucopyranoside and higenamine might be the main bioactive antimigraine constituents of ARR. This work provides valuable information on elucidation of the bioactive and anti-migraine principles of ARR. However, the actual contributions of naringenin7-O- $\beta$-D-glucopyranoside and higenamine to the anti-migraine effect of ARR need for further investigation.

\section{DECLARATIONS}

\section{Acknowledgement}

This work was financially supported by the
Academic Backbone Project of "Xinglin Scholars" (no. XSGG-2019023), the Young Scholars Project of "Xinglin Scholars" (no. QNXZ2019024), the Poverty Alleviation Project of Science and Technology Department of Sichuan Province (no. 2018NFP0112), the Guangxi Key Laboratory of Zhuang and Yao Ethnic Medicine "Gui Ke Ji Zi" (no. [2014]32), and the Collaborative Innovation Centre of Zhuang and Yao Ethnic Medicine "Gui Jiao Scientific Research" (no. [2013]20).

\section{Conflicts of interest}

No conflict of interest is associated with this work.

\section{Contribution of authors}

We declare that this work was done by the authors named in this article and all liabilities pertaining to claims relating to the content of this article will be borne by the authors. Gui-Hua Jiang conceived and designed the study. Ting Huang and Zhong-Hua Dai collected and analyzed the data. Ting Huang, Zhong-Hua Dai, Fei Long, Yu-Tian Lei and Mao-Hua Yuan performed the experiments. Gui-Hua Jiang wrote the manuscript. Ting Huang and Zhong-Hua Dai contributed equally to this work and should be considered as co-first authors. All authors read and approved the final manuscript.

\section{Open Access}

This is an Open Access article that uses a funding model which does not charge readers or their institutions for access and distributed under the terms of the Creative Commons Attribution License (http://creativecommons.org/licenses/by/ 4.0) and the Budapest Open Access Initiative (http://www.budapestopenaccessinitiative.org/rea d), which permit unrestricted use, distribution, and reproduction in any medium, provided the original work is properly credited.

\section{REFERENCES}

1. Silberstein SD. Migraine. Lancet 2004; 363(9406): 381391.

2. International Headache Society. The international classification of headache disorders (3rd edition). Cephalalgia 2018; 38(1): 1-211.

3. Dodick DW. Migraine. Lancet 2018; 391(10127): 13151330.

4. Xiao Y, Yuan L, Liu Y, Sun X, Cheng J, Wang T, Li F, Luo $R$, Zhao $X$. Traditional Chinese patent medicine for prophylactic treatment of migraine: a meta-analysis of

Trop J Pharm Res, May 2021; 20(5): 993 
randomized, double-blind, placebo-controlled trials. Eur J Neurol 2015; 22(2): 361-368.

5. Kloft C, Trame MN, Ritter CA. Systems pharmacology in drug development and therapeutic use - A forthcoming paradigm shift. Eur J Pharm Sci 2016; 94: 1-3.

6. Hopkins AL. Network pharmacology: the next paradigm in drug discovery. Nat Chem Biol 2008; 4(11): 682-690.

7. Li S, Fan TP, Jia W, Lu AP, Zhang WD. Network pharmacology in traditional chinese medicine. Evid Based Complement Alternat Med 2014; 2014: 138460.

8. Hu W, Fu W, Wei $X$, Yang Y, Lu C, Liu Z. A network pharmacology study on the active ingredients and potential targets of Tripterygium wilfordii Hook for treatment of rheumatoid arthritis. Evid Based Complement Alternat Med 2019; 2019: 5276865.

9. Ma L, Zhong $M$, Jiang $G$, Long $F, W u W$, Jiang $Y$. Elucidation of the active ingredients of Lamiophlomis herba against hemorrhage based on network pharmacology and tail snipping model in mice. Pharmazie 2020; 75: 381-384.

10. Jiang $Y$, Zhong $M$, Long $F$, Yang R. Deciphering the active ingredients and molecular mechanisms of Tripterygium hypoglaucum (Levl.) Hutch against rheumatoid arthritis based on network pharmacology. Evid Based Complement Alternat Med 2020; 2020: 2361865.

11. Jiang $Y$, Zhong $M$, Long $F$, Yang $R$, Zhang $Y$, Liu $T$. Network pharmacology-based prediction of active ingredients and mechanisms of Lamiophlomis rotata (Benth.) Kudo against rheumatoid arthritis. Front Pharmacol 2019; 10: 1435.

12. European Parliament. Directive 2010/63/EU, [cited 2021 Jan 27]. Available from: https://eurlex.europa.eu/LexUriServ/LexUriServ.do?uri=OJ:L:2010: 276:0033:0079:en:PDF

13. Jiang YB, Zhong M, Huang T, Dai ZH, Tao XB, Yang RP. Network pharmacology-based elucidation of the molecular mechanism underlying the anti-migraine effect of Asari Radix et Rhizoma. Trop J Pharm Res 2019; 18(10): 2067-2074.
14. Zhang Q, Liu GM, Li MQ, Geng YH. Synthesis of dodecenyl succinic anhydride. J Hebei Univ Technol 2005; 34(6): 39-42.

15. $X u Y, W u S$, Wu Y, Gong $M$, Wang Z. Recognition and optimization of ingredients treating nitroglycerin-induced migraine rats from Wuzhuyu Decoction. Evid Based Complement Alternat Med 2019; 2019: 6156754.

16. Gao Z, Liu X, Yu S, Zhang Q, Chen Q, Wu Q, Liu J, Sun $B$, Fang $L$, Lin J, et al. Electroacupuncture at acupoints reverses plasma glutamate, lipid, and LDLNLDL in an acute migraine rat model: $A 1 H$ NMR-based metabolomic study. Evid Based Complement Alternat Med 2014; 2014: 659268.

17. Li JC, Shen XF, Meng XL, Zhang Y, Lai XR. Analgesic effect and mechanism of tcche three TCM-herbal drugcombination Tou Feng Yu pill on treatment of migraine. Phytomedicine 2011; 18(8-9): 788-794.

18. Julia V, Buéno L. Tachykininergic mediation of viscerosensitive responses to acute inflammation in rats: role of CGRP. Am J Physiol 1997; 272(1): G141-G146.

19. Thomsen LL, Kruuse C, Iversen HK, Olesen J. A nitric oxide donor (nitroglycerin) triggers genuine migraine attacks. Eur J Neurol 1994; 1(1): 73-80.

20. Hamel E. The biology of serotonin receptors: focus on migraine pathophysiology and treatment. Can J Neurol Sci 1999; 26 (Suppl 3): S2-S6.

21. Yang $T H$, Zhang Q, Zhou MK, Liu YH, Zhou D. Effects of Tianshu capsule on the plasma levels of $\beta$-endorphin and 5-Hydroxytryptamine and c-fos expression of brain tissue in rats with migraine. J Clin Neurol 2008; 21(5): 368-370.

22. Hamel E. Serotonin and migraine: biology and clinical implications. Cephalalgia 2007; 27(11): 1293-1300.

23. Srikiatkhachorn A, Suwattanasophon C, Ruangpattanatawee U, Phansuwan-Pujito P. 5-HT2A receptor activation and nitric oxide synthesis: a possible mechanism determining migraine attacks. Headache 2002; 42(7): 566-574.

24. Shin JY, Roh SG, Lee NH, Yang KM. Ischemic necrosis of upper lip, and all fingers and toes after norepinephrine use. J Craniofac Surg 2016; 27(2): 453454. 